\title{
EDITORIAL
}

\section{Lupus eritematoso sistémico: una mirada especial en Colombia}

\section{Systemic lupus erythematosus: a special look in Colombia}

\author{
Olier-Castillo Doris, ${ }^{1}$
}

Las enfermedades autoinmunes son una condición crónica iniciada por una pérdida de la tolerancia a autoantígenos. La naturaleza crónica de estas enfermedades tiene un impacto significante en términos de los cuidados médicos, costos directos e indirectos y calidad de vida. La incidencia estimada para enfermedades autoinmunes es alrededor de 90 casos por 100.000 personas al año y su prevalencia es cerca del 3\% de la población. Aunque son de etiología desconocida se acepta que en su desarrollo participan factores genéticos y ambientales [1].

Como prototipo de enfermedades autoinmunes se encuentra el Lupus Eritematoso Sistémico (LES), considerado como una enfermedad multisistémica que se presenta mayoritariamente en mujeres en edad reproductiva con un fuerte componente étnico [2]. Estudios realizados en New York muestran que las afroamericanas son tres veces más susceptibles a desarrollar el LES que las de raza blanca [3]. Además se considera que es difícil separar el factor socioeconómico como un factor predisponente en la morbilidad de estos pacientes. Así, la población blanca que vive en los Estados unidos o en el Reino Unido parece tener un mejor pronóstico que la población asiática que ha emigrado a estos países. Estudios recientes realizados en América Latina en pacientes adultos con LES mostraron que la población mestiza multiétnica presentó casos más severos que los pacientes de origen Europeo puro [4].

Aunque la etiología y mecanismo patogénico del LES no ha sido claramente elucidado se acepta que es una patología multifactorial, resultante de la interacción compleja de factores genéticos y ambientales [5]. Se caracteriza por la producción de autoanticuerpos y la formación y depósito de complejos inmunes. Los autoanticuerpos se han asociado a la patogénesis y, el depósito en vasos sanguíneos de los complejos inmunes y

\footnotetext{
1 Bact, MSc. Editora revista Ciencia y Salud Virtual. Facultad de Ciencias de la Salud, Corporación Universitaria Rafael Núñez, Cartagena - Colombia.
} 
complemento, a la instalación del proceso inflamatorio en diversos órganos y sistemas como riñón, piel, sistema cardiovascular, sistema nervioso, entre otros. Esta diversidad de eventos inmunológicos es la causa de las diferentes manifestaciones clínicas y complicaciones en el LES [6,7]. Para el diagnóstico es indispensable el hallazgo de autoanticuerpos como los Anticuerpos Antinucleares (ANA), importantes en la muerte celular por la formación de complejos inmunes; los anti-DNA de doble cadena (dsDNA) ya que su presencia define el perfil inmunológico del paciente; y los anti-Sm y anti-RNP que son complejos de ribonucleoproteínas que participan en el procesamiento de ARN $[6,8]$.

En Colombia, a diferencia de otros países, los pacientes con LES mueren principalmente por las complicaciones de tipo renal [4]. Por tanto, es muy importante además de los autoanticuerpos mencionados, la determinación de otros que también contribuyen a la lesión glomerular. Entre estos se encuentran anti-SS-A/Ro, anti-SSB/La, anti-PRibosomal [9-12]. Los anti-alfa-actinina también se han asociado con antidsDNA en LES. En pacientes adultos, se han encontrado más significativamente asociados con la glomerulonefritis y con la actividad de la enfermedad los anti-alfaactinina que los antidsDNA [13].

Otro tipo de autoanticuerpo relacionado con la NL es el anti-lipoproteína lipasa (antiLPL) del cual se ha reportado estar presente en el $40 \%$ de pacientes con LES y además estar relacionado con altos niveles de triglicéridos séricos, por lo que también ha llamado la atención debido a su posible papel en la aceleración de la aterosclerosis en el LES. En pacientes adultos que presentan anti-LPL y anti-P ribosomal, se ha encontrado una asociación mucho más fuerte con la nefritis [14].

\section{BIBLIOGRAFÍA}

1. Anaya JM, Gomez LM, Castiblanco J. Is there a common genetic basis for autoimmune diseases? Clinical \& Developmental Immunology 2006; 13: 185-195.

2. Crow MK. Collaboration, Genetic Associations, and Lupus Erythematosus. N Engl J Med 2008; 358: 9, 956-961.

3. Sánchez-Rodríguez SH, Barajas-Vásquez GE, Ramírez-Alvarado ED, Moreno-García A, BarbozaCisneros OY. Lupus Eritematoso: enfermedad autoimmune sistémica y órgano específica. Rev Biomed 2004; 15: 173-180.

4. Vilá LM, Molina MJ, Mayor AM, Peredo RA, Santaella ML, Vilá S. Clinical and prognostic value of autoantibodies in Puerto Ricans with systemic lupus erythematosus. Lupus 2006; 15: 892-898.

5. Chung SA, Taylor KE, Graham RR, Nititham J, Lee AT, Ortmann WA, et al. Differential Genetic Associations for Systemic Lupus Erythematosus Based on Anti-dsDNA Autoantibody Production. PLoS Genet 2011; 7: 1-11.

6. Ardoin SP, Pisetsky D. Developments in the scientific understanding of lupus. Arthritis Research \& Therapy 2008; 10: 218.

7. Crispín JC, Liossis SNC, Kis-Toth K, Lieberman LA, Kyttaris VC, Juang YT1, et al. Pathogenesis of human systemic lupus erythematosus: recent advances. Trends Mol Med 2010; 16: 47-57.

8. Manson JJ, Ma A, Rogers P, Mason LJ, Berden JH3, van der Vlag J, et al. Relationship between antidsDNA, anti-nucleosome and anti-alpha-actinin antibodies and markers of renal disease in patients with lupus nephritis: a prospective longitudinal study. Arthritis Research \& Therapy 2009; 11: 1-9.

9. Stinton LM, Barr SG, Tibbles LA, Yilmaz S, Sar A, Benedikttson H, et al. Autoantibodies in lupus nephritis patients requiring renal transplantation. Lupus 2007; 15: 394-400.

10. Pradhan VD, Patwardhan MM, Ghosh K. Anti-nucleosome antibodies as a disease marker in systemic lupus erythematosus and its correlation with disease activity and other autoantibodies. IJDVL 2010; 76: 145-149. 
11. Hanrotel-Saliou C, Segalen I, Le Meur Y, Youinou P, Renaudineau I. Glomerular Antibodies in Lupus Nephritis. Clinic Rev Allerg Immunol 2011; 40:151-158.

12. Agmon-Levin N, Gilburd B, Kivity S, Porat-Katz BS, Flitman-Katzevman I, Shoenfeld N. AntiRibosomal-P Antibodies in Lupus Patients and Healthy Controls: Evaluation of Three ELISA Assays. IMAJ 2009; 11: 403-406.

13. Renaudineau I, Deocharan B, Jousse S, Renaudineau E, Putterman C, Youinou Pierre. Antialphaactinin antibodies: A new marker of lupus nephritis. Autoimmunity Reviews 2007; 6: 464-468.

14. Fesmire J, Reichlin M, Reichlin M. Effects of autoimmune antibodies anti-LPL, anti-LDL and antiOXLDL on lipid metabolism and atherosclerosis in systemic lupus erythematosus. Rev Bras Reumatol 2010; 50: 539-551. 